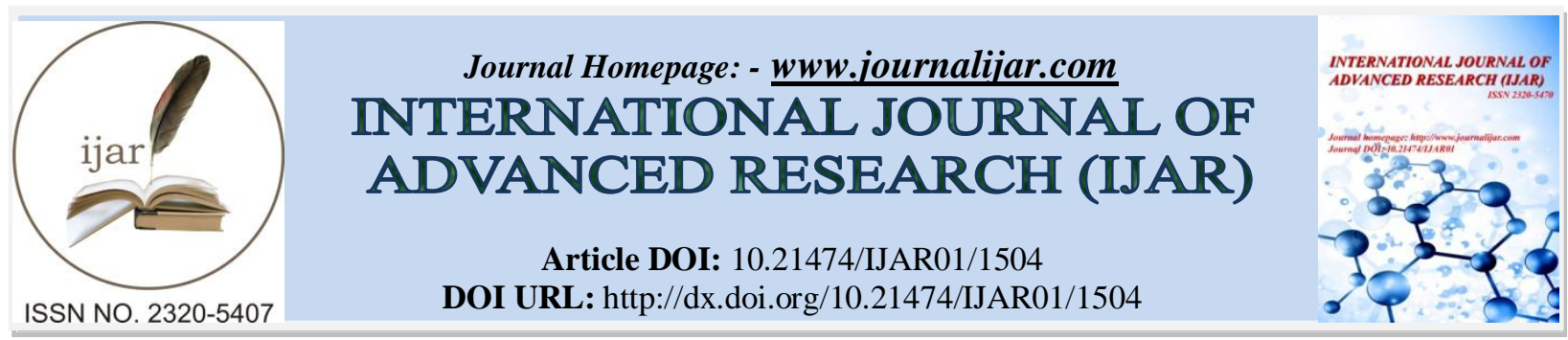

RESEARCH ARTICLE

\title{
MOBILE IRRIGATION SYSTEM.
}

\section{P.Aswini, Prof. G. Mallikarjuna Rao and Pavani Kollamudi.}

Department of Electronics \& Instrumentation, LakiReddy Balireddy of College of Engineering, L.B.Reddy Nagar, Mylavaram, Krishna Dt, AP-521230.

\section{Manuscript Info}

Manuscript History

Received: 19 July 2016

Final Accepted: 09 August 2016

Published: September 2016

Key words:-

dry run, SMS, sensor,Auto

control,Motor.

\section{Abstract}

Now-a-days the auto control of agricultural motor is very much needed because farmers are facing a main problem due to irregular power cuts at night time. Power ON, Power OFF of an agricultural motor is very difficult to the farmer because all the farmers are sleeping in the pump house (or) going to pump house during night times. We have implemented a new solution for protecting farmers against all the above mentioned difficulties. Here, the system detects the power ON state and sends an SMS to the user to switch ON the motor or not. The user can send SMS to switch ON the motor, the control system detects the message subsequently to power ON the motor. After that it analyzes the dry run (if water is not delivered) then it switches OFF the motor and sends an SMS for motor failure to the user. If the water flow is OK from the motor then it also sends an SMS to the user that the water flow is OK. One more facility we have added here is that, if any motor theft occurs it delivers an SMS to the user. For this purpose magnetic sensor has been used. If the water is sufficient for the field it turns OFF the motor automatically and sends an SMS to the user.

Copy Right, IJAR, 2016,. All rights reserved.

\section{Introduction:-}

The purpose of this project is to monitor and control the water flow to an irrigation system using Mobile Phone. This can be achieved by the use of water sensor, which senses the water content in the soil. This sensor output is given to a Microcontroller based control system for further data processing. The aim of this project is to provide an efficient solution for automatic control of irrigation motor with water sensor. Now a day's technology is running with time, it completely occupied the life style of human beings. Even though there is such an importance for technology in our routine life there are even people whose life styles are very far to this well-known term technology. So it is our responsibility to design few reliable systems which can be even efficiently used by them. This basic idea gave birth to the project GSM controlled soil moisture sensor. Here the automation process is done through the micro controller based technology.

In our project we make use of one microcontroller, which is dedicated at the water pump. The microcontroller forms the heart of the device and there are also water sensors, which are meant for detecting the moisture in the soil. Also GSM modem which will operates the water sensor. Here we are going to operate the water sensor. For this we will use GSM technology. To operate the sensor we should send a message to the GSM modem. That modem will receive the message and it will send the information to the microcontroller through decoder.Then the 
microcontroller will operate the sensor i.e., ON/OFF. The sensor will operate the motor according to the quantity of moisture in the soil. This process will be continued until we stop the sensor. Here we get the feedback of motor status i.e., ON/OFF in the form of message from the GSM modem present at the motor end. We will also receive an SMS in case of any internal problem.

The design of this system is very much sensitive and should be handled with utmost care because the microcontroller is a 5 volts device and it is employed to monitor the house hold power consumption per day where it should be interfaced with a 240 volts energy meter. So every small parameter should be given high importance while designing the interfacing circuit between the controller and the water motor.

\section{Methodology:-}

In GSM Based Automated Irrigation Control using automatic microcontroller in which the irrigation will take place only when there will be intense requirement of water that save a large quantity of water. These system brings a change to management of field resources where they developed a software stack called Android is used for mobile devices that include an operating system, middleware and key applications. These system covered lower range of agriculture land and not economically affordable. The System Supports excess Amount of water in the land and uses GSM to send message and an android app is been used they have used a methodology to overcome under irrigation, over irrigation that causes leaching and loss of nutrient content of soil they have also promised that Microcontroller used can increase System Life and lower the power Consumption. There system is just limited to the automation of irrigation system and lacks in extra ordinary features. In GSM based Automatic Irrigation Control System for Efficient Use of Resources and Crop Planning by Using an Android Mobile Pavithra D. S, M. S .Srinath.[2] States features of their system. The system supports water management decision, used for monitoring the whole system with GSM(RS-232) module .The system continuously monitors the water level (Water level Sensor) in the tank and provide accurate amount of water required to the plant or tree (crop). The system checks the temperature, and humidity of soil to retain the nutrient composition of the soil managed for proper growth of plant. Low cost and effective with less power consumption using sensors for remote monitoring and controlling devices which are controlled via SMS using a GSM using android mobile.

\section{Software requirements:-}

GLOBAL SYSTEM FOR MOBILE COMMUNICATION (GSM)

\section{Hardware requirements:-}

- Micro controller(AT89C52)

- GSM modem

- Design of PCB

- Water sensor

- Water sensor and micro controller interface

- Water full sensor

- Magnetic sensor

\section{Specifications:}

- Quad-Band 850/ 900/ 1800/ $1900 \mathrm{MHz}$

- $\quad$ GPRS multi-slot class $10 / 8$

- GPRS mobile station class B

- Compliant to GSM phase $2 / 2+$

- Class 4 (2 W @ 850/900 MHz)

- Class 1(1 W @ 1800/1900MHz)

- Dimensions: $24 * 24 * 3 \mathrm{~mm}$

- Weight: $3.4 \mathrm{~g}$

- Control via AT commands (GSM 07.07,07.05 and SIMCOM enhanced AT Commands)

- Low power consumption: $1.0 \mathrm{~mA}$ (sleep mode)

- Operation temperature: $-40^{\circ} \mathrm{C}$ to $+85^{\circ} \mathrm{C}$ 


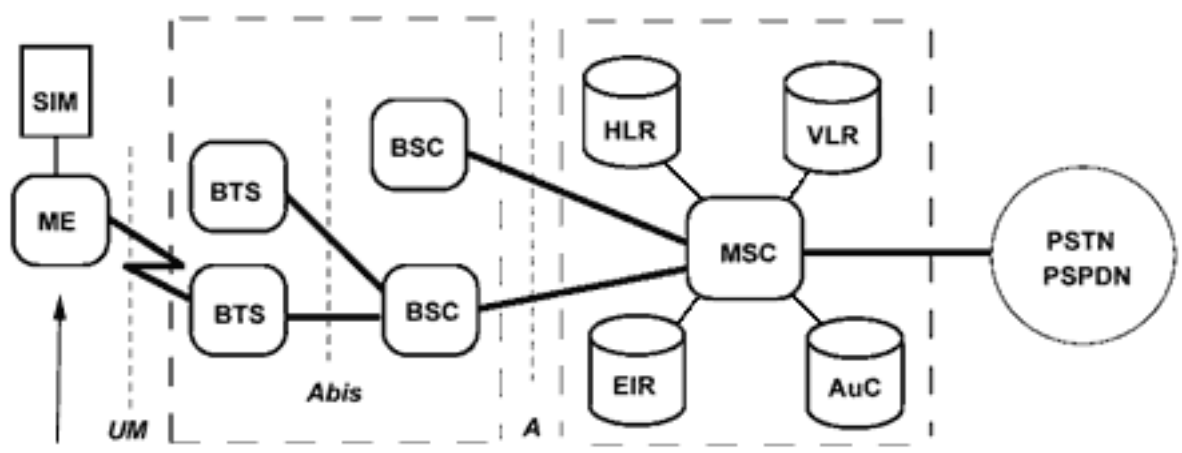

THE MOBLlE BASE STATION SUBSYSTEM NETWORK SUBSYSTEM

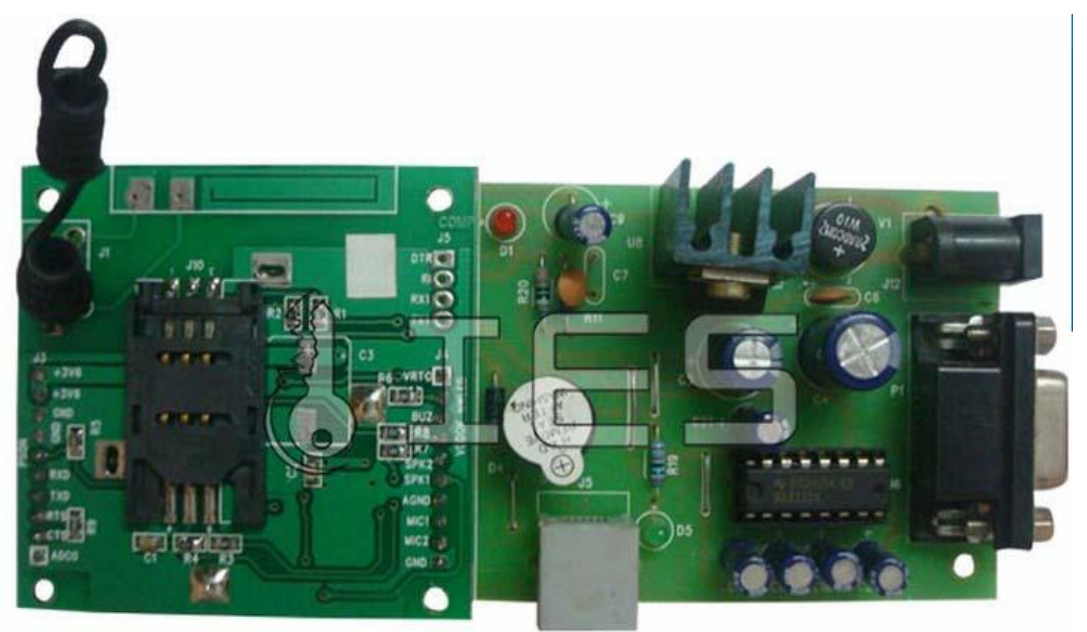

Projecy Code:-

Hardware System developed:-

AT_CMD: DB "POWER OK"

$\mathrm{DB} 1 \mathrm{AH}$

ORG 1B60H

ORG 1BA0H

AT_CMSS: DB "AT+CMSS=1"

ORG 1BCOH

AT_D: DB "ATD9491896606;"

ORG $1 \mathrm{COOH}$

AT_ERS: DB "AT+CMGD=1"

ORG $1 \mathrm{C} 10 \mathrm{H}$

AT_ERS2: DB "AT+CMGD=2"

ORG $1 \mathrm{C} 20 \mathrm{H}$

AT_ERS3: DB "AT+CMGD=3"

ORG $1 \mathrm{C} 30 \mathrm{H}$

AT_ERS4: DB "AT+CMGD=4"

ORG $1 \mathrm{C} 40 \mathrm{H}$

AT_ERS5: DB "AT+CMGD=5"

ORG $1 \mathrm{C} 50 \mathrm{H}$

AT_CNMI: DB "AT+CNMI=2,2,0,0,0"

ORG $1 \mathrm{C} 70 \mathrm{H}$

AT_CNMA: DB "AT+CNMA" 


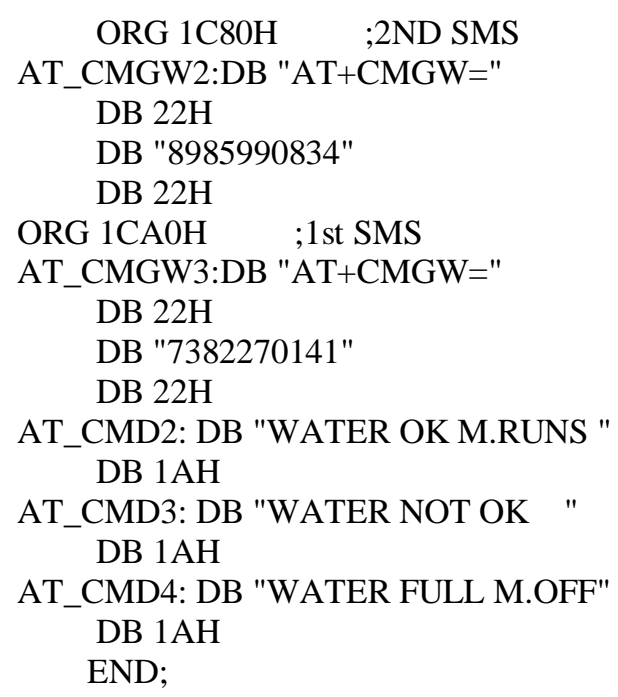

\section{Hardware System developed:-}

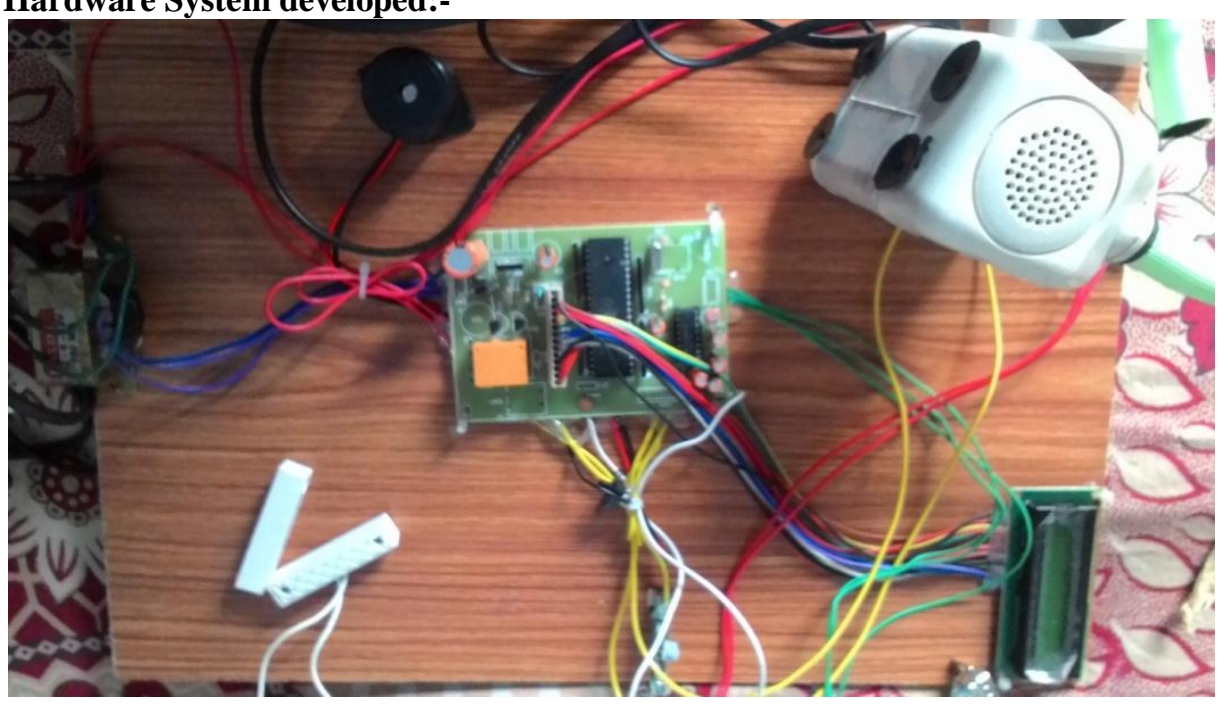

\section{Results:-}

Initially when the power is given to the system we will receive message as POWER OK, if we send message to ON the motor it will check whether the water is available or not if the water is available the motor will be ON and the output message will be as WATER OK MOTOR RUNS and if water is not available then we will receive message as WATER NOT OK, when the water is full automatically the motor will be OFF and we are having one special case that is when some one tries to theft the motor the magnetic sensors detects and sends output message as MOTOR THEFTED. 

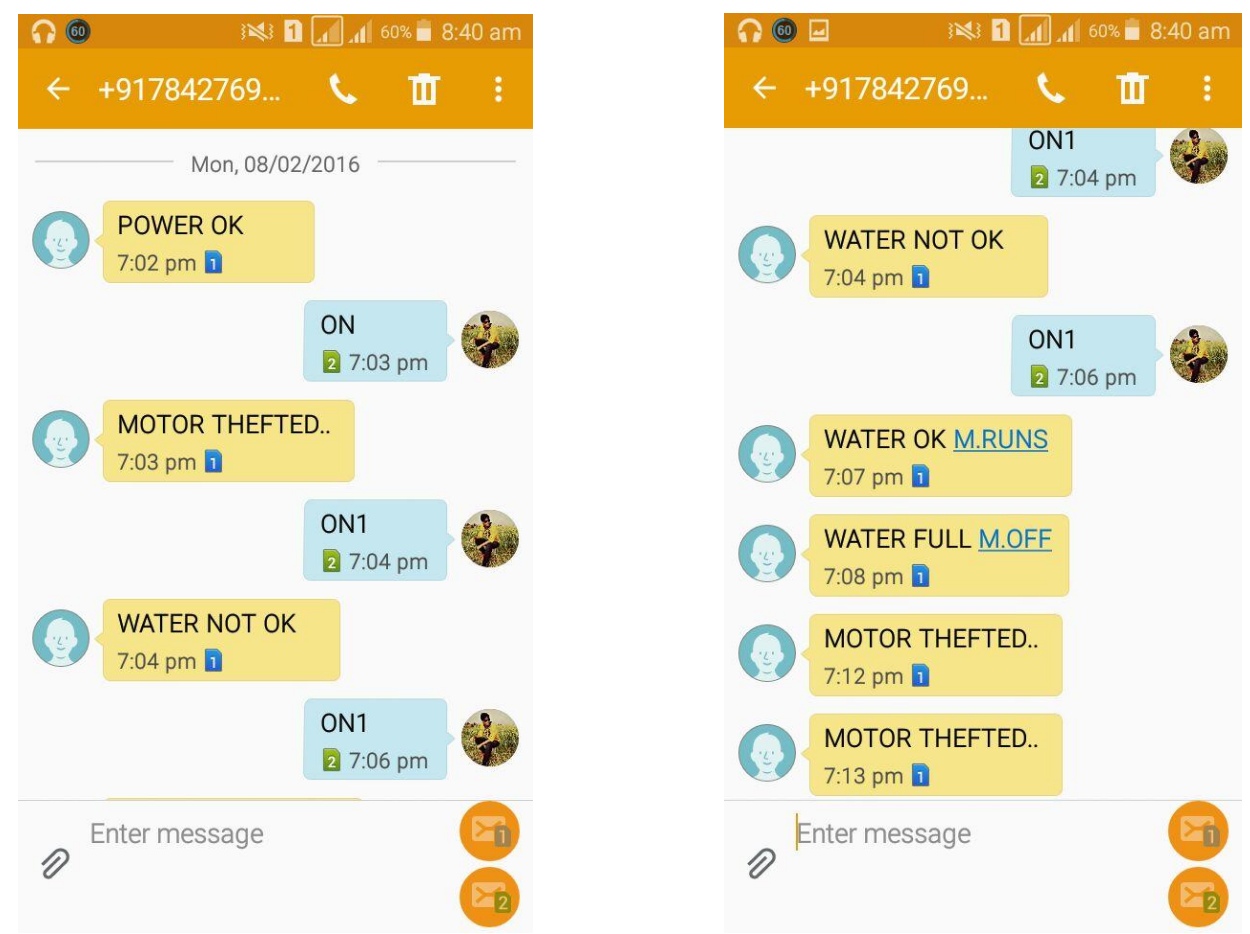

\section{Conclusion:-}

In this project the application we developed to control agricultural motor is very useful to the farmers. Mainly we made the application for sending and receiving SMS application based on GSM modem. OFF the motor, we know about status of power, about water pumping and also know about motor theft. The project serves as a guide to the users to better usage of electric power for their agriculture purpose and it reduces human effort. The operation is demonstrated successfully from the signals of GSM modem we can switch ON the motor or switch

\section{Future scope:-}

1. Further, we can get so many parameters by implementing the code like motor speed, current taking, power, voltage, frequency.

2. We can also fix a camera and record, so that we can know about motor working and also people thefting the motor.

\section{References:-}

1. Muhammad Ali Mazidi, Janice Gillespie Mazidi -THE 8051 MICROCONTROLLER \& EMBEDDED SYSTEM-PHI-2000.

2. Douglas V-Hall-MICROPROCESSORS \& INTERFACING-Tata MC Graw Hill publishing company limited1999, second edition.

3. A.K.Ray\&Burichand -ADVANCED MICROPROCESSOR \& PERIPHERALS-Tata MC Graw Hill publishing company limited-2000.

4. WILLIAM C.Y. LEE - MOBILE CELLULAR COMMUNICATIONS - Mc Graw Hill $-1982,2^{\text {nd }}$ edition. 